\title{
Consumer-Grade Wearable Device for Predicting Frailty in Canadian Home Care Service Clients: Prospective Observational Proof-of-Concept Study
}

\author{
Ben Kim ${ }^{1}$, PhD; Sandra M McKay ${ }^{2,3}, \mathrm{MBA}, \mathrm{PhD}$; Joon Lee ${ }^{4,5,6}, \mathrm{PhD}$ \\ ${ }^{1}$ School of Public Health and Health Systems, University of Waterloo, Waterloo, ON, Canada \\ ${ }^{2}$ VHA Home Healthcare, Toronto, ON, Canada \\ ${ }^{3}$ School of Physical Therapy, University of Toronto, Toronto, ON, Canada \\ ${ }^{4}$ Data Intelligence for Health Lab, Cumming School of Medicine, University of Calgary, Calgary, AB, Canada \\ ${ }^{5}$ Department of Community Health Sciences, Cumming School of Medicine, University of Calgary, Calgary, AB, Canada \\ ${ }^{6}$ Department of Cardiac Sciences, Cumming School of Medicine, University of Calgary, Calgary, AB, Canada
}

\section{Corresponding Author:}

Joon Lee, PhD

Data Intelligence for Health Lab

Cumming School of Medicine

University of Calgary

3280 Hospital Drive NW

Calgary, AB, T2N 4 Z6

Canada

Phone: 14032202968

Email: joonwu.lee@ucalgary.ca

\section{Abstract}

Background: Frailty has detrimental health impacts on older home care clients and is associated with increased hospitalization and long-term care admission. The prevalence of frailty among home care clients is poorly understood and ranges from $4.0 \%$ to $59.1 \%$. Although frailty screening tools exist, their inconsistent use in practice calls for more innovative and easier-to-use tools. Owing to increases in the capacity of wearable devices, as well as in technology literacy and adoption in Canadian older adults, wearable devices are emerging as a viable tool to assess frailty in this population.

Objective: The objective of this study was to prove that using a wearable device for assessing frailty in older home care clients could be possible.

Methods: From June 2018 to September 2019, we recruited home care clients aged 55 years and older to be monitored over a minimum of 8 days using a wearable device. Detailed sociodemographic information and patient assessments including degree of comorbidity and activities of daily living were collected. Frailty was measured using the Fried Frailty Index. Data collected from the wearable device were used to derive variables including daily step count, total sleep time, deep sleep time, light sleep time, awake time, sleep quality, heart rate, and heart rate standard deviation. Using both wearable and conventional assessment data, multiple logistic regression models were fitted via a sequential stepwise feature selection to predict frailty.

Results: A total of 37 older home care clients completed the study. The mean age was 82.27 (SD 10.84) years, and 76\% (28/37) were female; 13 participants were frail, significantly older $(P<.01)$, utilized more home care service $(P=.01)$, walked less $(P=.04)$, slept longer $(P=.01)$, and had longer deep sleep time $(P<.01)$. Total sleep time $(\mathrm{r}=0.41, P=.01)$ and deep sleep time $(\mathrm{r}=0.53, P<.01)$ were moderately correlated with frailty. The logistic regression model fitted with deep sleep time, step count, age, and education level yielded the best predictive performance with an area under the receiver operating characteristics curve value of 0.90 (Hosmer-Lemeshow $P=.88$ ).

Conclusions: We proved that a wearable device could be used to assess frailty for older home care clients. Wearable data complemented the existing assessments and enhanced predictive power. Wearable technology can be used to identify vulnerable older adults who may benefit from additional home care services.

(J Med Internet Res 2020;22(9):e19732) doi: 10.2196/19732 


\section{KEYWORDS}

frailty; mobile health; wearables; physical activity; home care; prediction; predictive modeling, older adults; activities of daily living, sleep

\section{Introduction}

Frailty has detrimental health impacts among community-dwelling older adults. Frailty is associated with higher mortality [1-3], functional impairment [4,5], hospitalization [2,3], long-term care facility admission [3], and disability in activities of daily living [4]. Frailty also increases the demand on formal and informal caregivers, including home and community care services and family members [6]. A recent study [7] identified that caregiver burden can be predicted based on the physical frailty level of geriatric patients. Due to its significant impact on health outcomes and its burden on health care systems, improved screening and monitoring of frailty for community-dwelling older adults is deemed vital [8].

The prevalence of frailty among community-dwelling older adults is poorly understood. A systematic review [9] reported that its prevalence ranges between $4.0 \%$ and $59.1 \%$; varying operational definitions and the heterogeneity of tools used in the studies resulted in a wide range of estimates. However, the prevalence range narrows to $4.0 \%$ to $17.0 \%$ when only the prevalence of physical phenotype frailty is aggregated by excluding social or cognitive deficits [9].

Both home and community health care are challenged with increased demand, primarily due to the aging population and emphasis on aging-in-place [10]. The demand for home and community health care service is expected to continue to rise in an effort to keep patients in their own community to reduce health care costs [11]. Screening and monitoring frailty in this population can benefit the home and community health care sector in multiple ways. Effective frailty intervention programs involve lifestyle changes including improving nutrition, increasing physical activity, and modifying the home environment [12]. Home and community health care clinicians are uniquely situated to deliver and monitor such interventions in a longitudinal manner, which can contribute to successful lifestyle changes. Screening for frailty at the community level can also help the home and community health care sector to identify vulnerable groups and allocate resources more efficiently [13].

Tools to screen community-dwelling older adults for frailty exist, but they have been used inconsistently and are often impractical or have been invalidated [14]. Wearable devices have been suggested as a potential tool to monitor frailty, and a few research studies [15-18] have explored this possibility. These studies explored the feasibility of using research-grade wearable devices, such as ActiGraph or independently developed wearable devices. These studies provide evidence for the internal construct validity of research-grade wearable devices to screen for frailty [19], as well as for a strong association between varying sleep quality parameters and frailty [20-22]. Consumer-grade wearable devices are a promising tool to monitor frailty as they have become smaller, cheaper, and ever more accessible in recent years [23], with older adults being the fastest growing group of wearable device users [24]. Research studies [25-27] have demonstrated the reliability of these devices for measuring step count, sleep quality, and heart rate compared to gold standard measures that are used in laboratory and clinical settings. Further validation studies demonstrated a high agreement between consumer-grade and medical-grade devices among specific populations, including patients with chronic obstructive pulmonary disease [28], pediatric patients [29], patients in intensive care units [30], and patients in cardiac rehabilitation [31].

Recognizing the need for an innovative solution to measure frailty in community-dwelling older adults, we set out to investigate the possibility of using consumer-grade wearable devices. We examined the data generated from a wearable device worn by home care clients to identify associations with frailty. We also aimed to identify key wearable device measures that can predict the status of frailty. Study procedure, tools, and statistical analyses are described. The results of the study are then presented, followed by a discussion where new findings are interpreted and compared to existing knowledge. The implications for frailty research studies, for wearable device research studies, and in home and community health care sectors, as well as the limitations of the study are presented.

\section{Methods}

\section{Study Design}

A prospective observational study was conducted to meet the study objectives. Participants were asked to wear a wearable device for a minimum of 8 days. At the end of the study, participants were assessed for frailty, activities of daily living, and level of comorbidity.

\section{Recruitment}

Home care clients in the Greater Toronto Area were recruited through VHA Home Healthcare from August 2018 to September 2019. VHA Home Healthcare is a home care agency that serves over 3000 clients throughout the Greater Toronto Area and other metropolitan areas in Ontario, Canada. Patients 55 years or older who had been receiving personal support service for more than 3 months were eligible for the study. Patients who were diagnosed with primary neuromuscular pathology, dependent on wheelchair, in an end-of-life program, or had cognitive impairments that could interfere with the use of wearable devices were excluded. Eligible home care patients were identified using VHA's electronic medical record system.

\section{Wearable Device}

The Xiaomi Mi Band Pulse 1S (Mi Band, hereafter) is a commercially available wearable device that is worn on the wrist. It uses a triaxial accelerometer to capture motions to approximate step count and sleep events. It is equipped with an optical heart rate sensor (photoplethysmography) to measure minute-by-minute heart rate. While the Mi Band can be worn on either the wrist or neck (as a pendant), its placement was 
limited to the wrist for the study. The reliability and internal consistency of Mi Band's performance for measuring step count when walking and jogging has been validated [32,33]. Wrist-worn wearable devices displayed systematically lower heart rate during exercise, but the Mi Band demonstrated the highest accuracy [32].

We collected daily step count, light sleep time, deep sleep time, total sleep time, awake time, sleep quality, mean heart rate, and heart rate standard deviation. Sleep quality was calculated as the percentage of sleep duration over total sleep time; sleep duration was determined by subtracting awake time from total sleep time [34,35]. Heart rate was measured in beats per minute. A pool of 10 devices were used in rotation and sanitized throughout the study. The adherence to wearing the device was defined as 10 hours or more of wear time per day [36].

\section{Frailty Assessment}

Frailty was assessed using the Fried Frailty Index, a tool that has been developed for and used widely with community-dwelling older adults [1]. The Fried Frailty Index assesses phenotypic frailty based on 5 criteria: weight loss, exhaustion, slowness, weakness, and low physical activity. The index categorizes frailty into 3 stages based on the number of criteria that are met: nonfrail, prefrail, and frail corresponding to scores of $0,1-2$, and 3-5, respectively [1]. We dichotomized the Fried Frailty Index into a frail group for those with a score of 3 or higher and a nonfrail group for those with a score of 2 or lower [1].

\section{Other Variables}

Sociodemographic variables were collected using a short background questionnaire and through review of the patient's medical chart. These sociodemographic variables included age, sex, weight, height, ethnicity, level of education, income, and marital status. The level of comorbidity was assessed using the Charlson Comorbidity Index (CCI) [37]. The level of activities of daily living was assessed with the Katz index of independence [38]. The number of hours of service received per week was collected by reviewing the patient's medical chart.

\section{Statistical Analysis}

Descriptive statistics and univariate comparisons of means, medians, and proportions were performed to describe the sociodemographic information and patient assessments according to their frailty status. The level of education was condensed into 2 levels: high school (some or completed) and postsecondary. Household income was categorized into a lower income, those who earned $\$ 30,000$ (approximately US \$22,653) per year or less, and higher income, those who earned $\$ 30,000$ or higher per year. Ethnicity was categorized into 2 levels: Caucasian and others which included aboriginal identity, Latin American, African American, South Asian, Southeast Asian, East Asian, Filipino, Arab, and West Asian.

Wearable device data were examined for participants adherence level, and days with less than 10 hours of wear time were excluded. Heart rate measurements of zero were generated when the device failed to have good skin contact. Such measurements were treated as missing and were removed from the analyses.
The Shapiro-Wilk test was performed to check for normality. To check for significant differences between patients who were frail and patients who were nonfrail, when the assumption of normal distribution was met, a two-tailed independent $t$ test was used, while the Mann-Whitney $U$ test was performed otherwise. The chi-square test was performed for categorical variables. The posthoc chi-square test was performed when significance was observed.

Pearson and Spearman correlation statistics were used to examine the relationship between frailty, sociodemographic information, patient assessments, and the data collected from the wearable devices.

Multiple logistic regression models were generated to predict frailty status. A sequential stepwise feature selection method was used to select the variables to be fitted into the models. The feature selection was used on the pool of sociodemographic and patient assessment variables to determine the features to be included in model 1 . Model 2 was built by applying feature selection to the variables derived from the wearable device data. Model 3 used all available variables in a feature selection algorithm; the selected variables were used to build the logistic regression model. The Hosmer-Lemeshow test was performed to test the goodness-of-fit for each model. The predictive performance of each model was evaluated and compared using the area under the receiver operating characteristics curve (AUROC).

Statistical significance was set at $\alpha=.05$ for all statistical results. The significance level for posthoc tests was corrected using the Bonferroni method. All statistical analyses were performed using R (version 3.6.0) in R studio (version 1.2.1335; R Studio Inc). Stepwise feature selection was performed using the function (stepAIC, version 7.3-51.4) from the MASS library [39].

\section{Ethics, Consent, and Permissions}

This study received ethics approval from the Office of Research Ethics Board at the University of Waterloo (ORE22842).

\section{Results}

\section{Recruitment}

A total of 72 older adults responded to the mailed recruitment brochure. All 72 older adults were contacted, and 45 agreed to participate in the study; 4 participants withdrew before completion of the 8-day study period. Data attrition due to technical issues resulted in data from 4 participants not being included. In total, 37 older home care clients were included in the study.

\section{Participant Characteristics}

Participants were 57 to 96 years of age, with a mean age of 82.23 (SD 10.84) years and 76\% (28/37) were female (Table $1)$. The prevalence of frailty among the study population was $35 \%$ (13/37). On average, participants were observed for 9.43 (SD 1.99) days. Participants who were frail (mean age: 83.92 years) were significantly older $(P<.001)$ than those who were nonfrail (mean age: 80.61 years). There was a significant difference in the income level between older adults who were 
frail and those who were nonfrail $(P=.03)$. Posthoc comparisons within each of the 3 income levels showed no statistical significance (low income: $P=.93$; mid to high income: $P>.999$ ) after correcting the $\alpha$ level with the Bonferroni method. Frail patients received significantly greater hours of home care services per week compared to the hours received by patients who were nonfrail $(P=.01)$. The resulting $P$ values of the Shapiro-Wilk normality tests are presented in Multimedia Appendix 1. The results of group difference tests are presented in Multimedia Appendix 2.

Table 1. Baseline sociodemographic and patient characteristics stratified by frailty status.

\begin{tabular}{|c|c|c|c|}
\hline Characteristics & Frail $(n=13)$ & Nonfrail $(n=24)$ & $P$ value \\
\hline Age (years), mean (SD) & $83.92(9.66)$ & $80.61(13.96)$ & $<.001^{\mathrm{a}}$ \\
\hline Sex, n (\%) & & & $>.999^{\mathrm{b}}$ \\
\hline Male & $3(23)$ & $6(25)$ & \\
\hline Female & $10(77)$ & $18(75)$ & \\
\hline BMI $\left(\mathrm{kg} / \mathrm{m}^{2}\right)$, mean $(\mathrm{SD})$ & $26.96(6.70)$ & $28.54(5.43)$ & $.44^{\mathrm{c}}$ \\
\hline $\mathrm{ADL}^{\mathrm{d}}$ score, mean $(\mathrm{SD})$ & $4.62(1.45)$ & $5.08(0.88)$ & $.43^{\mathrm{a}}$ \\
\hline $\mathrm{CCI}^{\mathrm{e}}$ score, mean (SD) & $1.92(1.26)$ & $1.25(1.11)$ & $.11^{\mathrm{a}}$ \\
\hline Marital status, n (\%) & & & $.29^{\mathrm{b}}$ \\
\hline Single & $1(8)$ & $7(29)$ & \\
\hline Divorced or separated & $2(15)$ & $5(21)$ & \\
\hline Widowed & $4(31)$ & $7(29)$ & \\
\hline Currently married & $6(46)$ & $5(21)$ & \\
\hline Education, n (\%) & & & $.12^{\mathrm{b}}$ \\
\hline High school or less & $8(62)$ & $7(29)$ & \\
\hline Postsecondary or higher & $5(38)$ & $17(71)$ & \\
\hline Income, n (\%) & & & $.03^{\mathrm{b}}$ \\
\hline Prefer not to answer & $7(54)$ & $3(12)$ & $.06^{\mathrm{f}}$ \\
\hline Low income & $4(31)$ & $13(54)$ & $.93^{\mathrm{f}}$ \\
\hline Mid to high income & $2(15)$ & $8(33)$ & $>.999^{\mathrm{f}}$ \\
\hline Ethnicity, n (\%) & & & $.71^{\mathrm{b}}$ \\
\hline White & $10(77)$ & $21(88)$ & \\
\hline Other & $3(23)$ & $3(12)$ & \\
\hline Personal support service, hours per week & $5.15(3.51)$ & $2.77(1.85)$ & $.01^{\mathrm{a}}$ \\
\hline
\end{tabular}

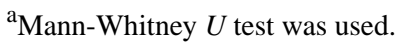

${ }^{\mathrm{b}}$ Chi-square test was used.

${ }^{\mathrm{c}}$ An independent $t$ test was used.

${ }^{\mathrm{d}}$ ADL: activities of daily living; Katz index of independence was used.

${ }^{\mathrm{e}} \mathrm{CCI}$ : Charlson Comorbidity Index.

${ }^{\mathrm{f}}$ Posthoc chi-square test was used.

\section{Frailty and Wearable Device Data}

On average, older adults wore the device for 20.03 (1.64) hours per day (Table 2). Home care clients who were frail reported significantly lower daily step counts than their nonfrail counterparts did (mean steps per day: 367.11 vs. 1023.95,

respectively; $P=.04)$. Total sleep time $(P=.01)$ and deep sleep time $(P<.01)$ were significantly longer for older adults who were frail, but no difference was found for light sleep time $(P=.04)$. No difference was found for heart rate measures. Box plots corresponding to Table 2 are presented in Multimedia Appendix 3. 
Table 2. Difference in the data collected from the wearable device between frail and nonfrail participants.

\begin{tabular}{|c|c|c|c|}
\hline Measures & Frail $(n=13)$, mean $(S D)$ & Nonfrail $(n=24)$, mean (SD) & $P$ value \\
\hline Worn time (hours per day) & $20.66(1.03)$ & $19.69(1.82)$ & $.16^{\mathrm{a}}$ \\
\hline Daily step count & $367.11(272.63)$ & $1023.95(863.83)$ & $.04^{\mathrm{a}}$ \\
\hline \multicolumn{4}{|l|}{ Sleep measures } \\
\hline Deep sleep time (minutes) & $138.90(64.00)$ & $75.65(39.12)$ & $<.001^{\mathrm{a}}$ \\
\hline Light sleep time (minutes) & $350.88(130.56)$ & $312.78(82.32)$ & $.35^{\mathrm{b}}$ \\
\hline Total sleep time (minutes) & $489.78(139.54)$ & $388.44(93.28)$ & $.01^{\mathrm{a}}$ \\
\hline Awake time (minutes) & $36.03(24.27)$ & $65.05(57.97)$ & $.17^{\mathrm{a}}$ \\
\hline Sleep quality $(\%)$ & $92.48(5.62)$ & $78.95(26.53)$ & $.08^{\mathrm{a}}$ \\
\hline Heart rate $(\mathrm{bpm})$ & $82.77(10.25)$ & $77.43(8.66)$ & $.13^{\mathrm{b}}$ \\
\hline Heart rate SD (bpm) & $22.12(7.61)$ & $18.78(4.54)$ & $.17^{\mathrm{b}}$ \\
\hline
\end{tabular}

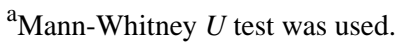

${ }^{\mathrm{b}}$ An independent $t$ test was used.

\section{Factors Correlated With Frailty}

The correlation between wearable data and frailty is summarized in Table 3. Daily step count was negatively correlated with frailty level $(r=-0.52, P<.001)$. All 5 sleep measures were moderately correlated with frailty. Education level was moderately correlated with frailty status $(r=-0.40, P=.02)$. No relationship was found between heart rate measures and frailty status. 
Table 3. Correlations between wearable device data, patient characteristics, and frailty.

\begin{tabular}{|c|c|c|}
\hline & Frailty & \\
\hline & Correlation coefficient & $P$ value \\
\hline Daily step count & -0.52 & .001 \\
\hline \multicolumn{3}{|l|}{ Sleep measures } \\
\hline Total sleep time & 0.52 & .001 \\
\hline Deep sleep time & 0.47 & .003 \\
\hline Light sleep time & 0.35 & .03 \\
\hline Sleep quality & 0.56 & $<.001$ \\
\hline Awake time & -0.54 & $<.001$ \\
\hline \multicolumn{3}{|l|}{ Heart rate measures } \\
\hline Mean heart rate & 0.11 & .54 \\
\hline Heart rate SD & -0.25 & .16 \\
\hline \multicolumn{3}{|l|}{ Sociodemographic } \\
\hline Age & 0.29 & .08 \\
\hline Sex & 0.074 & .66 \\
\hline BMI & -0.068 & .69 \\
\hline Income level & -0.066 & .74 \\
\hline Education level & -0.40 & .02 \\
\hline \multicolumn{3}{|l|}{ Patient assessments } \\
\hline $\mathrm{ADL}^{\mathrm{a}}$ score & -0.18 & .27 \\
\hline $\mathrm{CCI}^{\mathrm{b}}$ score & 0.16 & .33 \\
\hline Personal support hours & 0.23 & .17 \\
\hline
\end{tabular}

${ }^{a} A D L$ : activities of daily living; Katz index of independence was used.

${ }^{b} \mathrm{CCI}$ : Charlson Comorbidity Index.

\section{Frailty Prediction}

\section{Model Description}

A total of 3 multiple variable logistic regression models were fitted to predict frailty with the sociodemographic variables, patient assessments, and wearable data (Table 4). Income was excluded from the feature selection method since a high number of participants declined to answer. Model 1 formulation began by fitting the sociodemographic variables and patient assessments. The feature selection method resulted in a model that contains CCI and education level. Model 2 used variables derived from the wearable device data only. The resulting model was fitted with step count, deep sleep time, awake time, and heart rate standard deviation. Model 3 used all available variables and was fitted with deep sleep time, step count, age, and education level.

Table 4. Three frailty prediction models and the variables selected by the stepwise feature selection method.

\begin{tabular}{lll}
\hline Models & Variable pool & Selected variables \\
\hline Model 1 & Sociodemographic and patient assessment variables & CCI $^{\mathrm{a}}$, education level \\
Model 2 & Wearable device-derived variables & $\begin{array}{l}\text { Step count, deep sleep time, light sleep time, heart rate standard } \\
\text { deviation }\end{array}$ \\
Model 3 & $\begin{array}{l}\text { Sociodemographic, patient assessment, and wearable device-de- } \\
\text { rived variables }\end{array}$ & Deep sleep time, step count, age, education level \\
\hline
\end{tabular}

${ }^{\mathrm{a} C C I}$ : Charlson Comorbidity Index.

\section{Model Evaluation}

Table 5 shows the results of multiple logistic regression analyses and the factors predictive of frailty. Model 1 showed no significant association. For model 2, deep sleep time was a significant predictor of frailty $(P<.01)$. Increasing deep sleep time was significantly associated with increased odds of frailty (adjusted odds ratio [OR] 1.02, 95\% CI 1.01-1.05, $P<.01$ ). For 
model 3, deep sleep time $(P=.02)$ and age $(P=.03)$ were significant predictors. Increasing deep sleep time was associated with an increase in the odds of frailty (adjusted OR 1.03, 95\% CI 1.01-1.07, $P=.02$ ), whereas increasing age was associated with a decrease in the odds of frailty (adjusted OR $0.90,95 \%$ CI 0.80-0.99, $P=.03$ ).

All 3 models were evaluated for their goodness of fit using the Hosmer-Lemeshow statistic. Overall, no model showed statistical significance on this test, indicating they had acceptable goodness-of-fit, and the predicted frailty matched the observed frailty status (Table 6).

When the predictive performance was evaluated by AUROC, all 3 models showed medium to high values. Model 1 (AUROC 0.77), based on sociodemographic and patient assessment variables, was outperformed by model 2 (AUROC 0.88 ), which was fitted with wearable device variables. Model 3 (AUROC 0.90) had the best predictive performance (Table 6). The receiver operating characteristic curves are shown in Figure 1 for each model.

Table 5. Multiple logistic regression of factors associated with frailty.

\begin{tabular}{|c|c|c|}
\hline Model and variables & Adjusted $\mathrm{OR}^{\mathrm{a}}(95 \% \mathrm{CI})$ & $P$ value \\
\hline \multicolumn{3}{|l|}{ Model 1} \\
\hline $\mathrm{CCI}^{\mathrm{b}}$ & $1.78(0.95,3.66)$ & .09 \\
\hline Education level—high school or below & reference & - \\
\hline Education level—postsecondary education or higher & $0.22(0.04,0.96)$ & .05 \\
\hline \multicolumn{3}{|l|}{ Model 2} \\
\hline Step count & $1.00(1.00,1.00)$ & .17 \\
\hline Deep sleep time & $1.02(1.01,1.05)$ & .02 \\
\hline Awake time & $0.97(0.93,1.01)$ & .18 \\
\hline Heart rate standard deviation & $1.17(0.99,1.46)$ & .10 \\
\hline \multicolumn{3}{|l|}{ Model 3} \\
\hline Deep sleep time & $1.03(1.01,1.07)$ & .04 \\
\hline Step count & $1.00(1.00,1.00)$ & .06 \\
\hline Age & $0.90(0.80,0.99)$ & .04 \\
\hline Education level—high school or less & reference & - \\
\hline Education level—postsecondary education or higher & $0.11(0.01,0.94)$ & .06 \\
\hline
\end{tabular}

${ }^{\mathrm{a} O R}$ : odds ratio.

${ }^{\mathrm{b}} \mathrm{CCI}$ : Charlson Comorbidity Index.

Table 6. Summary of model performance in predicting frailty status.

\begin{tabular}{|c|c|c|c|c|c|}
\hline Models & Accuracy & Sensitivity & Specificity & AUROC $^{\mathrm{a}}$ & $\begin{array}{l}\text { Hosmer- } \\
\text { Lemeshow test } \\
P \text { value }\end{array}$ \\
\hline $\begin{array}{l}\text { Model 1: Sociodemographic and patient assessment } \\
\text { variables }\end{array}$ & 0.76 & 0.46 & 0.92 & 0.77 & 0.73 \\
\hline Model 2:Wearable device derived variables & 0.81 & 0.69 & 0.88 & 0.88 & 0.95 \\
\hline Model 3: All variables from models 1 and 2 & 0.81 & 0.69 & 0.88 & 0.90 & 0.85 \\
\hline
\end{tabular}

${ }^{\mathrm{a}}$ AUROC: area under the receiver operating characteristics curve. 
Figure 1. The receiver operating characteristics curves (with area under the curve) for all models fitted to predict frailty. AUC: area under the curve.

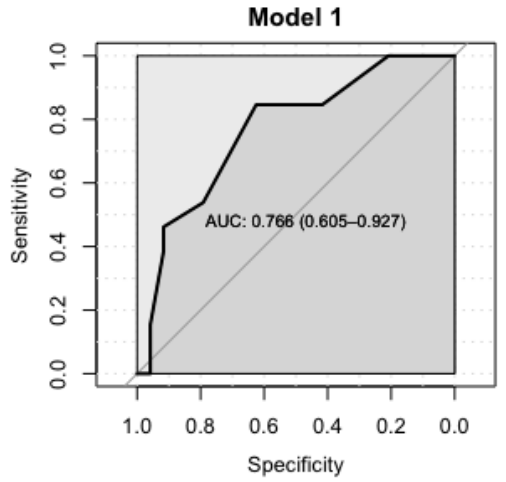

\section{Discussion}

\section{Principal Findings}

The growing aging population in Canada and the emphasis on aging-in-place call for innovative ways to improve efficiency in the home and community health care sector. There is an increasing interest in integrating information and communication technology such as consumer-grade wearable devices into health care delivery due to their rising popularity, ease-of-use, and the potential usefulness of continuously collected data [40]. The aim of this study was to investigate the possibility of assessing and predicting frailty using a wearable device.

We observed 37 older home care clients for a minimum of 8 days. The prevalence of frailty in the study sample, $35 \%$ (13/37), was similar to that found in other research studies examining home care clients [3,41]. Many research studies [9,42] reported a significantly higher prevalence of frailty in older women compared to prevalence in older men, but this was not observed in our study sample. However, another study [3] that examined the same population did not find any significant difference between the sexes. Overall, the study sample seemed reasonably representative of the home care population. Previous research studies $[1,43]$ reported an association between income and education level and frailty. Our study sample had significantly different income levels between the 2 frailty groups $(P=.03)$. However, the posthoc chi-square analysis results did not reach statistical significance (low income: $P=.93$; mid to high income: $P>$.999). Education level was moderately correlated with frailty level $(\mathrm{r}=-0.40, P=.02)$. Overall, our study sample displayed the general characteristics of frail populations $[1,43]$.

Our study found a significantly higher utilization of home care service by older adults who were frail compared to utilization by older adults who were nonfrail (mean hours per week: 5.15 vs $2.77 ; P=.01$ ). Unfortunately, the current system fails to meet all care needs of home care clients as indicated by the increased hours of informal care and caregiver distress for the home care clients with more severe frailty [13]. Resulting adverse health outcomes and increased health care utilization [3] highlight the need for a better allocation of home care service to those who stand to benefit the most.

In our study sample, older adults who were nonfrail walked significantly more than the older adults who were frail. This result is in line with the findings of previous research studies

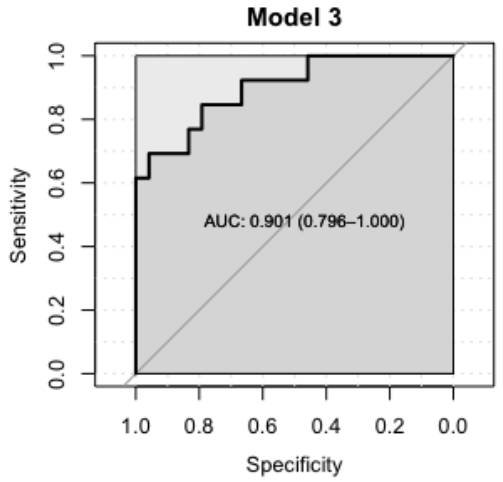

where reduced daily step count and physical activity were observed for frail community-dwelling older adults [44] and ICU patients [45]. In a previous study [46], daily step count was significantly related to frailty. Our study extended this evidence outside the controlled settings and beyond 24-hour monitoring period $[47,48]$, and demonstrated the relationship in an unsupervised setting.

Sleep measures including longer total sleep, deep sleep, and light sleep durations; awake time; and sleep quality were shown to be related to more severe frailty. This is contrary to the common knowledge of deterioration of sleep quality and quantity with aging [49]. However, in epidemiological studies, a longer sleep duration was associated with an increased risk of heart disease and all-cause mortality [50]. The lowest mortality risk was found for those who sleep about 7 hours a night [51], while men who slept more than 8 hours per day had a tripled risk of heart disease [52]. This relationship was shown in our study sample where older adults who were nonfrail and older adults who were frail had significantly different total sleep durations $(P=.01)$. Older adults who were nonfrail had a mean total sleep duration of 6.48 hours (close to 7 hours), while their frail counterparts slept for 8.16 hours. These findings demonstrate the additional information wearable devices provide over conventional sleep quality assessments.

In this study, we built logistic regression models using a sequential stepwise feature selection method. Feature selection in general can help improve predictive performance [53]. It minimizes the number of features needed in a model, which was critical given the small sample size of this study. While manual feature selection based on expert knowledge could have been a feasible alternative, our goal was to maximize frailty prediction performance in our data set by utilizing an empirical feature selection method. The analysis of multiple logistic regression models showed that wearable device data were a superior source of information for predicting frailty than sociodemographic information and patient assessments. However, the highest AUROC of 0.90 was achieved with the model that used wearable device data, sociodemographic, and patient assessment information. Previously, a similar study [16] that used a neck-worn wearable device to obtain step count and physical activity-related variables achieved an AUROC of 0.88 in discriminating the prefrail group from the frail and nonfrail groups. Another study [48] used 2 research-grade wearable devices concurrently and achieved an AUROC of 0.86 in 
discriminating 3 frailty states using stride length. Both studies were limited due to their short 48-hour observational period and being conducted in a laboratory setting. Our study demonstrated that unsupervised monitoring of frailty at home using a wearable device is possible. Our results corroborate that wearable technology should complement, rather than replace, the existing practice [54].

Many mobile health and telehealth apps have been successful at delivering health care while improving efficiency [55]. A study [56] that examined telehealth for frail older adults found the most cost-effective telehealth program used automated monitoring of vital signs to reduce health service use and facilitate remote follow-up. Wearable devices are becoming increasingly affordable and are capable of offering a similar use case as telehealth apps with their automated monitoring of physical activities, sleep, and heart rate. The range of information collected from wearable devices are also increasing with the advancement of sensor technology such as electrocardiogram, blood glucose level, oxygen saturation level, and electrodermal activity. When coupled with well-calibrated algorithms that enable early detection of health deteriorations such as frailty, cost savings can be further increased. The added value of wearable devices in assessing frailty for home care clients and community-dwelling older adults should be carefully evaluated for their feasibility in real-life settings. Each home or community health care system is unique, including but not limited to their target population, geographical area, and funding structure. Future research should consider these factors when evaluating the clinical value and cost savings of wearable devices.

Future research should confirm the predictive power of data derived from wearable devices and extend it beyond the home and community care sector. Our results indicated that wearable devices are a valid tool when an adequate analytical process is used. We recommend that future home care research studies leverage the potential of consumer-grade wearable devices to help identify vulnerable and frail groups who may benefit from additional home care services and increased access to health care.

\section{Limitations}

Our study has several limitations. First, the small study sample prevented us from stratifying patients into nonfrail, prefrail, and frail groups. A third frailty state could have helped us demonstrate gradient measures of wearable data. The small sample size also limited the number of variables that could be used in developing multiple logistic regression models. The 3 logistic regression models were each fitted with 2 to 4 features. They exceeded the common rule of 1-in-10 and which may have increased the risk of overfitting [57]. The small sample size precluded partitioning our data into training and test sets. As a result, the reported predictive performance overestimated the performance that would be found on a different sample of older adults. A further caution should be taken when interpreting the results of the Hosmer-Lemeshow test due to the small sample size.

Our research used an 8-day observation period. While this was longer than the observation periods of most other studies using wearable devices, an even longer observational period may be required to reveal new patterns that are not observable within 8 days such as weekdays versus weekends and seasonal differences. Lastly, the validation studies that examined the Mi Band [32,33] were conducted in younger participants, limiting their generalizability to older adults of this study.

\section{Conclusions}

In this study, we proved the concept of using a wrist-worn consumer-grade wearable device to assess frailty among older home care clients. Data collected from the wearable device, such as total sleep time and deep sleep time, were associated with frailty. The frailty prediction model based on variables selected from wearable devices, sociodemographic variable, and patient assessment variables achieved the highest AUROC of 0.90 , compared to the AUROC of the other predictive models that either used only sociodemographic and assessment variables or only wearable device-derived variables.

\section{Acknowledgments}

This work was supported by a Core Research Project Grant from the AGE-WELL Network of Centres of Excellence (WP7.3).

\section{Conflicts of Interest}

None declared.

\section{Multimedia Appendix 1}

The results of Shapiro-Wilk normality tests for all continuous variables.

[DOCX File, 15 KB-Multimedia Appendix 1]

\section{Multimedia Appendix 2}

$\mathrm{T}$ test statistics and chi-square test statistics for comparisons between the frail and nonfrail participants with respect to baseline sociodemographic and patient characteristics $(n=37)$.

[DOCX File, 17 KB-Multimedia Appendix 2] 


\section{Multimedia Appendix 3}

Boxplots of the wearable device data comparing frail and nonfrail participants. [DOCX File, $181 \mathrm{~KB}-$ Multimedia Appendix 3]

\section{References}

1. Fried LP, Tangen CM, Walston J, Newman AB, Hirsch C, Gottdiener J, et al. Frailty in older adults: evidence for a phenotype. J Gerontol A Biol Sci Med Sci 2001 Mar;56(3):M146-M156. [Medline: 11253156]

2. Shamliyan T, Talley KMC, Ramakrishnan R, Kane RL. Association of frailty with survival: a systematic literature review. Ageing Res Rev 2013 Mar;12(2):719-736. [doi: 10.1016/j.arr.2012.03.001] [Medline: 22426304]

3. Campitelli MA, Bronskill SE, Hogan DB, Diong C, Amuah JE, Gill S, et al. The prevalence and health consequences of frailty in a population-based older home care cohort: a comparison of different measures. BMC Geriatr 2016 Jul 07;16:133 [FREE Full text] [doi: 10.1186/s12877-016-0309-z] [Medline: 27388294]

4. Vermeulen J, Neyens JCL, van RE, Spreeuwenberg MD, de WLP. Predicting ADL disability in community-dwelling elderly people using physical frailty indicators: a systematic review. BMC Geriatr 2011 Jul;11:33 [FREE Full text] [doi: 10.1186/1471-2318-11-33] [Medline: 21722355]

5. Fried LP, Ferrucci L, Darer J, Williamson JD, Anderson G. Untangling the concepts of disability, frailty, and comorbidity: implications for improved targeting and care. J Gerontol A Biol Sci Med Sci 2004 Mar;59(3):255-263. [Medline: 15031310]

6. Sinha M. Portrait of caregivers, 2012. Statistics Canada Catalogue no. 89-652-X. Ottawa: Statistics Canada; 2013 Sep. URL: https://www150.statcan.gc.ca/n1/pub/89-652-x/89-652-x2013001-eng.pdf [accessed 2018-06-13] [WebCite Cache ID 709i6D5LK]

7. Ringer TJ, Hazzan AA, Kennedy CC, Karampatos S, Patterson C, Marr S, et al. Care recipients' physical frailty is independently associated with subjective burden in informal caregivers in the community setting: a cross-sectional study. BMC Geriatr 2016 Nov 17;16(1):186 [FREE Full text] [doi: 10.1186/s12877-016-0355-6] [Medline: 27855633]

8. Muscedere J, Andrew MK, Bagshaw SM, Estabrooks C, Hogan D, Holroyd-Leduc J, et al. Screening for Frailty in Canada's Health Care System: A Time for Action. Can. J. Aging 2016 May 23;35(3):281-297. [doi: 10.1017/s0714980816000301]

9. Collard RM, Boter H, Schoevers RA, Oude VRC. Prevalence of frailty in community-dwelling older persons: a systematic review. J Am Geriatr Soc 2012 Aug;60(8):1487-1492. [doi: 10.1111/j.1532-5415.2012.04054.x] [Medline: 22881367]

10. Home health care and related services, 2017. Statistics Canada Catalogue no. 11-001-X. Ottawa: Statistics Canada; 2019 31. URL: https://www150.statcan.gc.ca/n1/en/daily-quotidien/190731/dq190731c-eng.pdf?st=siWEGqn7 [accessed 2020-05-05]

11. Integration through information communication technology for home care in Canada: Final Report. Canadian Home Care Association. Ottawa: The Canadian Home Care Association; 2008 Mar. URL: https://cdnhomecare.ca/wp-content/uploads/ 2020/03/Information-Technology-in-Home-Care-March-2008-English.pdf [accessed 2019-04-21]

12. Puts MTE, Toubasi S, Andrew MK, Ashe MC, Ploeg J, Atkinson E, et al. Interventions to prevent or reduce the level of frailty in community-dwelling older adults: a scoping review of the literature and international policies. Age Ageing 2017 May 01;46(3):383-392 [FREE Full text] [doi: 10.1093/ageing/afw247] [Medline: 28064173]

13. Maxwell CJ, Campitelli MA, Diong C, Mondor L, Hogan DB, Amuah JE, et al. Variation in the health outcomes associated with frailty among home care clients: relevance of caregiver distress and client sex. BMC Geriatr 2018 Sep 12;18(1):211 [FREE Full text] [doi: 10.1186/s12877-018-0899-8] [Medline: $\underline{\text { 30208884] }}$

14. Dwyer JT, Gahche JJ, Weiler M, Arensberg MB. Screening Community-Living Older Adults for Protein Energy Malnutrition and Frailty: Update and Next Steps. J Community Health 2019 Sep 30;45(3):640-660. [doi: 10.1007/s10900-019-00739-1]

15. Rumer KK, Saraswathula A, Melcher ML. Prehabilitation in our most frail surgical patients. Current Opinion in Organ Transplantation 2016;21(2):188-193. [doi: 10.1097/mot.0000000000000295]

16. Razjouyan J, Naik A, Horstman M, Kunik M, Amirmazaheri M, Zhou H, et al. Wearable Sensors and the Assessment of Frailty among Vulnerable Older Adults: An Observational Cohort Study. Sensors 2018 Apr 26;18(5):1336. [doi: 10.3390/s18051336]

17. Mohler MJ, Wendel CS, Taylor-Piliae RE, Toosizadeh N, Najafi B. Motor Performance and Physical Activity as Predictors of Prospective Falls in Community-Dwelling Older Adults by Frailty Level: Application of Wearable Technology. Gerontology 2016 Apr 30;62(6):654-664. [doi: 10.1159/000445889]

18. Parvaneh S, Mohler J, Toosizadeh N, Grewal GS, Najafi B. Postural Transitions during Activities of Daily Living Could Identify Frailty Status: Application of Wearable Technology to Identify Frailty during Unsupervised Condition. Gerontology 2017 Mar 11;63(5):479-487. [doi: 10.1159/000460292]

19. Chen S, Honda T, Chen T, Narazaki K, Haeuchi Y, Supartini A, et al. Screening for frailty phenotype with objectively-measured physical activity in a west Japanese suburban community: evidence from the Sasaguri Genkimon Study. BMC Geriatr 2015 Apr 02;15:36 [FREE Full text] [doi: 10.1186/s12877-015-0037-9] [Medline: 25887474]

20. Nóbrega PVDN, Maciel ACC, de Almeida Holanda CM, Oliveira Guerra R, Araújo JF. Sleep and frailty syndrome in elderly residents of long-stay institutions: a cross-sectional study. Geriatr Gerontol Int 2014 Jul;14(3):605-612. [doi: 10.1111/ggi.12144] [Medline: 24020502] 
21. Ensrud KE, Blackwell TL, Redline S, Ancoli-Israel S, Paudel ML, Cawthon PM, Osteoporotic Fractures in Men Study Group. Sleep disturbances and frailty status in older community-dwelling men. J Am Geriatr Soc 2009 Nov;57(11):2085-2093 [FREE Full text] [doi: 10.1111/j.1532-5415.2009.02490.x] [Medline: 19793160 ]

22. Vaz Fragoso CA, Gahbauer EA, Van Ness PH, Gill TM. Sleep-wake disturbances and frailty in community-living older persons. J Am Geriatr Soc 2009 Nov;57(11):2094-2100 [FREE Full text] [doi: 10.1111/j.1532-5415.2009.02522.x] [Medline: $\underline{19793356]}$

23. Baig MM, Afifi S, GholamHosseini H, Mirza F. A Systematic Review of Wearable Sensors and IoT-Based Monitoring Applications for Older Adults - a Focus on Ageing Population and Independent Living. J Med Syst 2019 Jun 15;43(8):233. [doi: 10.1007/s10916-019-1365-7] [Medline: 31203472]

24. Older Americans Drive Growth of Wearables Internet. eMarketer. 2018 Dec 13. URL: https://www.emarketer.com/content/ older-americans-drive-growth-of-wearables [accessed 2019-10-11]

25. Evenson KR, Goto MM, Furberg RD. Systematic review of the validity and reliability of consumer-wearable activity trackers. Int J Behav Nutr Phys Act 2015;12(1):159 [FREE Full text] [doi: 10.1186/s 12966-015-0314-1] [Medline: 26684758]

26. Shcherbina A, Mattsson CM, Waggott D, Salisbury H, Christle JW, Hastie T, et al. Accuracy in Wrist-Worn, Sensor-Based Measurements of Heart Rate and Energy Expenditure in a Diverse Cohort. J Pers Med 2017 May 24;7(2):3 [FREE Full text] [doi: 10.3390/jpm7020003] [Medline: 28538708]

27. Wang R, Blackburn G, Desai M, Phelan D, Gillinov L, Houghtaling P, et al. Accuracy of Wrist-Worn Heart Rate Monitors. JAMA Cardiol 2016 Oct 12:104-106. [doi: 10.1001/jamacardio.2016.3340] [Medline: 27732703]

28. Vooijs M, Alpay LL, Snoeck-Stroband JB, Beerthuizen T, Siemonsma PC, Abbink JJ, et al. Validity and usability of low-cost accelerometers for internet-based self-monitoring of physical activity in patients with chronic obstructive pulmonary disease. Interact J Med Res 2014;3(4):e14 [FREE Full text] [doi: 10.2196/ijmr.3056] [Medline: 25347989]

29. Voss C, Gardner RF, Dean P, Harris K. Validity of Commercial Activity Trackers in Children With Congenital Heart Disease. Can J Cardiol 2017 Jun;33(6):799-805. [doi: 10.1016/j.cjca.2016.11.024] [Medline: 28347581]

30. Kroll RR, Boyd JG, Maslove DM. Accuracy of a Wrist-Worn Wearable Device for Monitoring Heart Rates in Hospital Inpatients: A Prospective Observational Study. J Med Internet Res 2016 Sep 20;18(9):e253 [FREE Full text] [doi: 10.2196/jmir.6025] [Medline: 27651304]

31. Alharbi M, Bauman A, Neubeck L, Gallagher R. Validation of Fitbit-Flex as a measure of free-living physical activity in a community-based phase III cardiac rehabilitation population. Eur J Prev Cardiol 2016 Sep;23(14):1476-1485. [doi: 10.1177/2047487316634883] [Medline: 26907794]

32. Ricchio K, Lyter-Antonneau P, Palao J. Reliability of Fitness Trackers at Different Prices for Measuring Steps and Heart Rate: a Pilot Study. Central European Journal of Sport Sciences and Medicine 2018;24:57-64. [doi: 10.18276/cej.2018.4-06]

33. Paradiso C, Colino F, Liu S. The Validity and Reliability of the Mi Band Wearable Device for Measuring Steps and Heart Rate. Int J Exerc Sci 2020;13(4):689-701 [FREE Full text] [Medline: 32509127]

34. Kroll RR, McKenzie ED, Boyd JG, Sheth P, Howes D, Wood M, WEARable Information Technology for hospital INpatients (WEARIT-IN) study group. Use of wearable devices for post-discharge monitoring of ICU patients: a feasibility study. J Intensive Care 2017;5:64 [FREE Full text] [doi: 10.1186/s40560-017-0261-9] [Medline: 29201377]

35. Duncan MJ, Vandelanotte C, Trost SG, Rebar AL, Rogers N, Burton NW, et al. Balanced: a randomised trial examining the efficacy of two self-monitoring methods for an app-based multi-behaviour intervention to improve physical activity, sitting and sleep in adults. BMC Public Health 2016 Dec 30;16:670 [FREE Full text] [doi: 10.1186/s12889-016-3256-x] [Medline: 27473327]

36. Tudor-Locke C, Barreira TV, Schuna JM, Mire EF, Chaput J, Fogelholm M, ISCOLE Research Group. Improving wear time compliance with a 24-hour waist-worn accelerometer protocol in the International Study of Childhood Obesity, Lifestyle and the Environment (ISCOLE). Int J Behav Nutr Phys Act 2015 Feb 11;12:11 [FREE Full text] [doi: 10.1186/s12966-015-0172-x] [Medline: 25881074]

37. Katz JN, Chang LC, Sangha O, Fossel AH, Bates DW. Can comorbidity be measured by questionnaire rather than medical record review? Med Care 1996 Jan;34(1):73-84. [doi: 10.1097/00005650-199601000-00006] [Medline: 8551813]

38. Katz S, Downs TD, Cash HR, Grotz RC. Progress in development of the index of ADL. Gerontologist 1970;10(1):20-30. [Medline: 5420677]

39. Venables W, Ripley B. Modern Applied Statistics with S, 4th Ed. New York: Springer-Verlag; 2002.

40. National Information Board. Personalised Health and Care 2020. Digital Health. 2014 Nov. URL: https://www. digitalhealth.net/includes/images/news0254/PDF/0172 NHS England NIB Report WITH ADDITIONAL MATERIAL S8. pdf [accessed 2018-10-17] [WebCite Cache ID 73EQIHsy7]

41. Kelly S, O'Brien I, Smuts K, O'Sullivan M, Warters A. Prevalence of frailty among community dwelling older adults in receipt of low level home support: a cross-sectional analysis of the North Dublin Cohort. BMC Geriatr 2017 Jun 07;17(1):121 [FREE Full text] [doi: 10.1186/s12877-017-0508-2] [Medline: 28592236]

42. Avila-Funes JA, Helmer C, Amieva H, Barberger-Gateau P, Le Goff M, Ritchie K, et al. Frailty among community-dwelling elderly people in France: the three-city study. J Gerontol A Biol Sci Med Sci 2008 Oct;63(10):1089-1096 [FREE Full text] [doi: 10.1093/gerona/63.10.1089] [Medline: 18948560] 
43. St John PD, Montgomery PR, Tyas SL. Social position and frailty. Can J Aging 2013 Sep;32(3):250-259. [doi: 10.1017/S0714980813000329] [Medline: 23962524]

44. Cavanaugh JT, Coleman KL, Gaines JM, Laing L, Morey MC. Using step activity monitoring to characterize ambulatory activity in community-dwelling older adults. J Am Geriatr Soc 2007 Jan;55(1):120-124. [doi: 10.1111/j.1532-5415.2006.00997.x] [Medline: 17233695]

45. McNelly AS, Rawal J, Shrikrishna D, Hopkinson NS, Moxham J, Harridge SD, et al. An Exploratory Study of Long-Term Outcome Measures in Critical Illness Survivors: Construct Validity of Physical Activity, Frailty, and Health-Related Quality of Life Measures. Crit Care Med 2016 Jun;44(6):e362-e369. [doi: 10.1097/CCM.0000000000001645] [Medline: 26974547]

46. Theou O, Jakobi JM, Vandervoort AA, Jones GR. A comparison of physical activity (PA) assessment tools across levels of frailty. Arch Gerontol Geriatr 2012;54(3):e307-e314. [doi: 10.1016/j.archger.2011.12.005] [Medline: 22209454]

47. Cook DJ, Thompson JE, Prinsen SK, Dearani JA, Deschamps C. Functional recovery in the elderly after major surgery: assessment of mobility recovery using wireless technology. Ann Thorac Surg 2013 Sep;96(3):1057-1061. [doi: 10.1016/j.athoracsur.2013.05.092] [Medline: 23992697]

48. Schwenk M, Mohler J, Wendel C, D'Huyvetter K, Fain M, Taylor-Piliae R, et al. Wearable sensor-based in-home assessment of gait, balance, and physical activity for discrimination of frailty status: baseline results of the Arizona frailty cohort study. Gerontology 2015;61(3):258-267 [FREE Full text] [doi: 10.1159/000369095] [Medline: 25547185]

49. Espiritu JRD. Aging-Related Sleep Changes. Clinics in Geriatric Medicine 2008 Feb;24(1):1-14. [doi: 10.1016/j.cger.2007.08.007]

50. Gallicchio L, Kalesan B. Sleep duration and mortality: a systematic review and meta-analysis. J Sleep Res 2009 Jun;18(2):148-158 [FREE Full text] [doi: 10.1111/j.1365-2869.2008.00732.x] [Medline: 19645960]

51. Tamakoshi A, Ohno Y, JACC Study Group. Self-reported sleep duration as a predictor of all-cause mortality: results from the JACC study, Japan. Sleep 2004 Feb 01;27(1):51-54. [Medline: 14998237]

52. Burazeri G, Gofin J, Kark J. Over 8 hours of sleep--marker of increased mortality in Mediterranean population: follow-up population study. Croat Med J 2003 Apr;44(2):193-198 [FREE Full text] [Medline: 12698511]

53. Kassambara A. Machine Learning Essentials: Practical Guide in R. eBook: STHDA; 2008.

54. Fasano A, Mancini M. Wearable-based mobility monitoring: the long road ahead. Lancet Neurol 2020 May;19(5):378-379. [doi: 10.1016/S1474-4422(20)30033-8] [Medline: $\underline{32059810]}$

55. Iribarren SJ, Cato K, Falzon L, Stone PW. What is the economic evidence for mHealth? A systematic review of economic evaluations of mHealth solutions. PLoS One 2017 Feb;12(2):e0170581 [FREE Full text] [doi: 10.1371/journal.pone.0170581] [Medline: 28152012]

56. Barlow J, Singh D, Bayer S, Curry R. A systematic review of the benefits of home telecare for frail elderly people and those with long-term conditions. J Telemed Telecare 2016 Jun 23;13(4):172-179. [doi: 10.1258/135763307780908058]

57. Peduzzi P, Concato J, Kemper E, Holford TR, Feinstein AR. A simulation study of the number of events per variable in logistic regression analysis. J Clin Epidemiol 1996 Dec;49(12):1373-1379. [Medline: 8970487]

\section{Abbreviations \\ AUROC: area under the receiver operating characteristics curve \\ CCI: Charlson comorbidity index}

Edited by G Eysenbach; submitted 30.04.20; peer-reviewed by S Tedesco, M Bardus; comments to author 25.05.20; revised version
received 04.07.20; accepted 14.07.20; published 03.09.20
Please cite as:
Kim B, McKay SM, Lee J
Consumer-Grade Wearable Device for Predicting Frailty in Canadian Home Care Service Clients: Prospective Observational
Proof-of-Concept Study
J Med Internet Res 2020;22(9):e19732
URL: $\underline{\text { https://www.jmir.org/2020/9/e19732 }}$
doi: $\underline{10.2196 / 19732}$
PMID: $\underline{32880582}$

CBen Kim, Sandra M McKay, Joon Lee. Originally published in the Journal of Medical Internet Research (http://www.jmir.org), 03.09.2020. This is an open-access article distributed under the terms of the Creative Commons Attribution License (https://creativecommons.org/licenses/by/4.0/), which permits unrestricted use, distribution, and reproduction in any medium, provided the original work, first published in the Journal of Medical Internet Research, is properly cited. The complete bibliographic 
information, a link to the original publication on http://www.jmir.org/, as well as this copyright and license information must be included. 